\title{
AGE-RELATED SYNAPSE LOSS IN HIPPOCAMPAL CA3 IS NOT REVERSED BY CALORIC RESTRICTION
}

\author{
M. M. ADAMS, ${ }^{a, b, c *}$ H. S. DONOHUE, ${ }^{a}$ M. C. LINVILLE, ${ }^{a}$ \\ E. A. IVERSEN, ${ }^{a}$ I. G. NEWTON ${ }^{a, d}$ AND \\ J. K. BRUNSO-BECHTOLD ${ }^{\mathrm{a}, \mathrm{b}}$ \\ ${ }^{a}$ Departments of Neurobiology and Anatomy, Wake Forest University \\ School of Medicine, Medical Center Boulevard, Winston-Salem, NC \\ 27157-1010, USA \\ ${ }^{b}$ Roena Kulynych Center for Memory and Cognition Research, Wake \\ Forest University School of Medicine, Medical Center Boulevard, Win- \\ ston-Salem, NC 27157-1010, USA \\ ${ }^{\circ}$ Department of Psychology, Bilkent University, 06800 Bilkent, Ankara, \\ Turkey \\ ${ }^{d}$ Department of Radiology, University of California, San Diego, CA \\ 92103, USA
}

\begin{abstract}
Caloric restriction (CR) is a reduction of total caloric intake without a decrease in micronutrients or a disproportionate reduction of any one dietary component. While CR attenuates age-related cognitive deficits in tasks of hippocampal-dependent memory, the cellular mechanisms by which CR improves this cognitive decline are poorly understood. Previously, we have reported age-related decreases in key synaptic proteins in the CA3 region of the hippocampus that are stabilized by lifelong CR. In the present study, we examined possible age-related changes in the functional microcircuitry of the synapses in the stratum lacunosum-moleculare (SL-M) of the CA3 region of the hippocampus, and whether lifelong CR might prevent these age-related alterations. We used serial electron microscopy to reconstruct and classify SL-M synapses and their postsynaptic spines. We analyzed synapse number and size as well as spine surface area and volume in young (10 months) and old (29 months) ad libitum fed rats and in old rats that were calorically restricted from 4 months of age. We limited our analysis to SL-M because previous work demonstrated age-related decreases in synaptophysin confined to this specific layer and region of the hippocampus. The results revealed an agerelated decrease in macular axo-spinous synapses that was not reversed by $C R$ that occurred in the absence of changes in the size of synapses or spines. Thus, the benefits of CR for CA3 function and synaptic plasticity may involve other biological effects including the stabilization of synaptic proteins levels in the face of age-related synapse loss. (C) 2010 IBRO. Published by Elsevier Ltd. All rights reserved.
\end{abstract}

Key words: dietary restriction, electron microscopy, serial reconstruction, synapses, hippocampus, rat.

\footnotetext{
${ }^{*}$ Correspondence to: M. M. Adams, Psychology Department, Bilkent University, 06800 Bilkent, Ankara, Turkey. Tel: +90-312-290-1090; fax: +90-312-290-2561

E-mail address: michelle@bilkent.edu.tr (M. M. Adams).

Abbreviations: CR, caloric restriction; LTD, long-term depression; LTP, long-term potentiation; PSD, postsynaptic density; SL-M, stratum lacunosum-moleculare.
}

Progressive cognitive impairment is a hallmark of the aging process in rodents. In particular, cognitive functions mediated by the hippocampus decline across lifespan. Interestingly, old (29-32 months) rodents that have been calorically restricted starting from 4 months of age demonstrate better performance on the Morris Water Maze test of spatial learning and memory than their ad libitum-fed counterparts (Adams et al., 2008; Markowska and Savonenko, 2002). Although a broad range of anatomical, physiological, and biochemical studies have evaluated the effects of caloric restriction $(\mathrm{CR})$ on the brain, a complete understanding of the interaction between the aging-related and CR-mediated changes that underlie the attenuation of cognitive decline in old CR animals has remained elusive.

Glutamate receptors, synaptic proteins that underlie excitatory transmission and are linked to hippocampaldependent learning and memory, are stabilized by CR. Specifically, in contrast to ad libitum fed rats, tissue levels of the N-methyl-D-aspartate (NMDA) and alpha-amino-3hydroxy-5-methyl-4-isoxazole proprionic acid (AMPA) subunits of the glutamate receptor in rats fed $60 \%$ of ad libitum calories $(40 \% \mathrm{CR})$ are stabilized in dentate gyrus, CA1, and CA3 of the hippocampus across lifespan (Adams et al., 2008; Newton et al., 2007; Shi et al., 2007). CR also prevents age-related deficits in long-term potentiation (LTP), an NMDA-dependent process believed to underlie learning and memory (Eckles-Smith et al., 2000). In addition to stabilizing hippocampal function and glutamate receptor proteins, CR has been shown to positively regulate genes involved in energy metabolism, oxidative stress responses, and cell death, as well as growth factor levels such as BDNF (Martin et al., 2007, 2008 ; Newton et al., 2005). Although quantitative electron microscopic studies did not reveal an effect of CR on synapse number in the middle molecular layer of dentate gyrus (Newton et al., 2007) or in stratum radiatum of CA1 (Shi et al., 2007), no age-related synaptic decline was detected in those layers. Interestingly, in CA3 overall tissue levels of the essential synaptic protein synaptophysin declined with age and were significantly higher in CR than in ad libitum fed old rats (Adams et al., 2008).

Age-related synaptic changes in CA3, reflected as a decline in synaptophysin, have been associated with deficits in spatial learning and memory (Adams et al., 2008; Smith et al., 2000). Importantly, those changes were circuit-specific. When compared to young and aged-unimpaired rats, aged-impaired rats demonstrated a significantly lower level of synaptophysin immunoreactivity that was limited to stratum lacunosum-moleculare (SL-M), but not present if the immunoreactivity was averaged across different individual layers (Smith et al., 2000). Declines in 
synaptophysin have been associated with numerical decreases in synapses (Cabalka et al., 1992; Goto and Hirano, 1990; Heinonen et al., 1995; Masliah et al., 1993, $1994,1995)$, but could also be due to other factors such as a reduction in synapse size. Although synapse number can be determined from serial pairs of thin sections using unbiased stereology (Newton et al., 2007; Shi et al., 2007), the synaptic microcircuitry cannot. Importantly, the size and morphology of synapses and the structural features of their dendritic targets can only be determined from three-dimensional (3-D) reconstructions of serial thin sections. In the present study, we used 3-D serial reconstruction to explore the relationship between $\mathrm{CR}$ and age-related changes in the synaptic microcircuitry associated with cognitive function. Specifically, we have evaluated synapse number, size, and complexity as well as postsynaptic spine morphology in the SL-M of CA3 in young and old rats fed ad libitum and in old rats that were calorically restricted from 4 months of age.

\section{EXPERIMENTAL PROCEDURES}

The present study was designed to assess the functional architecture of the microcircuitry in the SL-M in the CA3 region of the hippocampus. SL-M was chosen for study because a selective decrease in synaptophysin correlated with an age-related cognitive decline has been reported in this layer of CA3 (Smith et al., 2000). In addition, we previously reported an age-related loss of CA3 synaptic proteins, including synaptophysin, which is prevented by CR (Adams et al., 2008). Accordingly, we used 3-D serial reconstruction to analyze the synaptic microcircuitry of SL-M including a quantitative assessment of synapse number as well as the size of synapses and postsynaptic spines. The advantage of this technique is that it permits evaluation of multiple parameters in a defined tissue volume. For example, we were able to determine if a decrease in synapse number was accompanied by a compensatory increase in the size of synapses or spines or if synapse morphology changed with age or diet.

\section{Experimental subjects}

Experimental animals for this study consisted of F1 male Fischer $344 \times$ Brown Norway $($ F $344 \times B N)$ rats obtained from the National Institute of Aging Caloric Restriction Colony (Harlan Laboratories, Indianapolis, IN, USA). The F $344 \times$ BN hybrid is a widely-used model for studies of aging and CR (Adams et al., 2008; Mayhew et al., 1998; Newton et al., 2005, 2007; Poe et al., 2001; Ramsey et al., 2004; Shi et al., 2002, 2007; Wetter et al., 1999) and demonstrates CR-mediated stabilization of learning and memory ability between middle and old age (Adams et al., 2008; Markowska and Savonenko, 2002). The present study included three groups of $\mathrm{F} 344 \times \mathrm{BN}$ rats ( $n=5 /$ group): ad libitum fed young (Y-AL, 10 months old) and old (O-AL, 29 months old) rats and calorically restricted old rats (O-CR, 29 months old). Rats were housed individually to monitor daily food intake. The animal facility at the Wake Forest University School of Medicine is fully accredited by the American Association for Accreditation of Laboratory Animal Care and complies with all Public Health Service, National Institutes of Health and institutional policies and standards for laboratory animal care. All experiments were conducted in accordance with Guidelines for the Care and Use of Experimental Animals, using protocols approved by the Institutional Animal Care and Use Committee at the Wake Forest University School of Medicine.

In the NIA Colony, all rats were fed ad libitum (NIH-31 diet) from weaning until 14 weeks of age. At 14 weeks, caloric intake for CR rats was reduced by $10 \%$ per week over 4 weeks, reaching a full $40 \%$ reduction by 17 weeks of age. The vitamin-fortified NIH-31 diet fed to CR rats provided $60 \%$ of the calories and $100 \%$ of the vitamins consumed by AL rats. The same dietary restriction regimen for the $\mathrm{CR}$ group was continued at our facility. All rats were fed daily, shortly before dark cycle onset, and had free access to water. Rats were weighed weekly, before feeding.

\section{Electron microscopy and three-dimensional reconstruction}

Details of tissue processing for electron microscopy have been published previously (Donohue et al., 2006; Stewart et al., 2005). Briefly, rats were anesthetized with ketamine/xylazine and perfused transcardially with fixative ( $2 \%$ paraformaldehyde/ $2 \%$ glutaraldehyde). Trapezoidal blocks of CA3 were cut from $200 \mu \mathrm{m}$ coronal vibratome sections through the dorsomedial hippocampus (Fig. 1A). The blocks were processed for electron microscopy, embedded in Araldite resin (Araldite 502 Embedding Kit, Ted Pella, Incorporated, Redding, CA, USA), and trimmed to include the full extent of the apical dendrites and the pyramidal cell layer of CA3 (Fig. 1B). Ultrathin sections (70 $\mathrm{nm}$ ) were cut using a Leica UCT ultramicrotome (Leica, Bannockburn, IL, USA). A ribbon of serial ultrathin sections from each animal was collected on formvar-coated copper slot grids and stained with uranyl acetate and lead citrate. Serial fields were photographed at $8,000 \times$ magnification using a Zeiss $10-C$ transmission electron microscope (Zeiss, Peabody, MA, USA).

Corresponding regions on serial electron photomicrographs of the CA3 SL-M were identified using fiducial markers. Electron micrograph negatives were digitally scanned and aligned using the Reconstruct program (software available from: http://synapses.
A

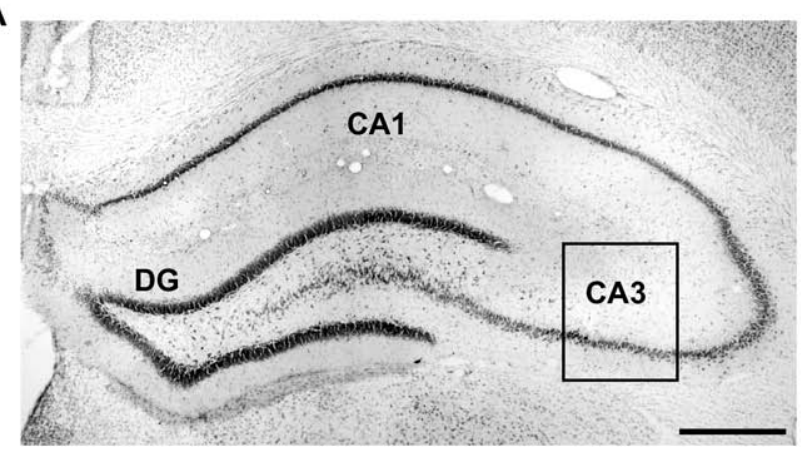

B

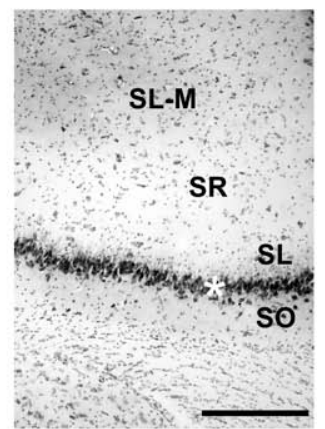

Fig. 1. Hippocampal regions and the location of stratum lacunosum-moleculare (SL-M) within CA3. (A) Low power photomicrograph of a coronal section through the dorsal hippocampus illustrating the dentate gyrus (DG), CA3, and CA1 regions in the Fischer 344×Brown Norway rat. (B) High power photomicrograph of a coronal section depicting the layers of hippocampal area CA3. Quantification of synapses and neurons was confined to SL-M. SL-M, stratum lacunosum-moleculare; SR, stratum radiatum; SL, stratum lucidum. * indicates pyramidal cell layer. Scale bars: (A) $300 \mu \mathrm{m}$ and (B) $150 \mu \mathrm{m}$. 

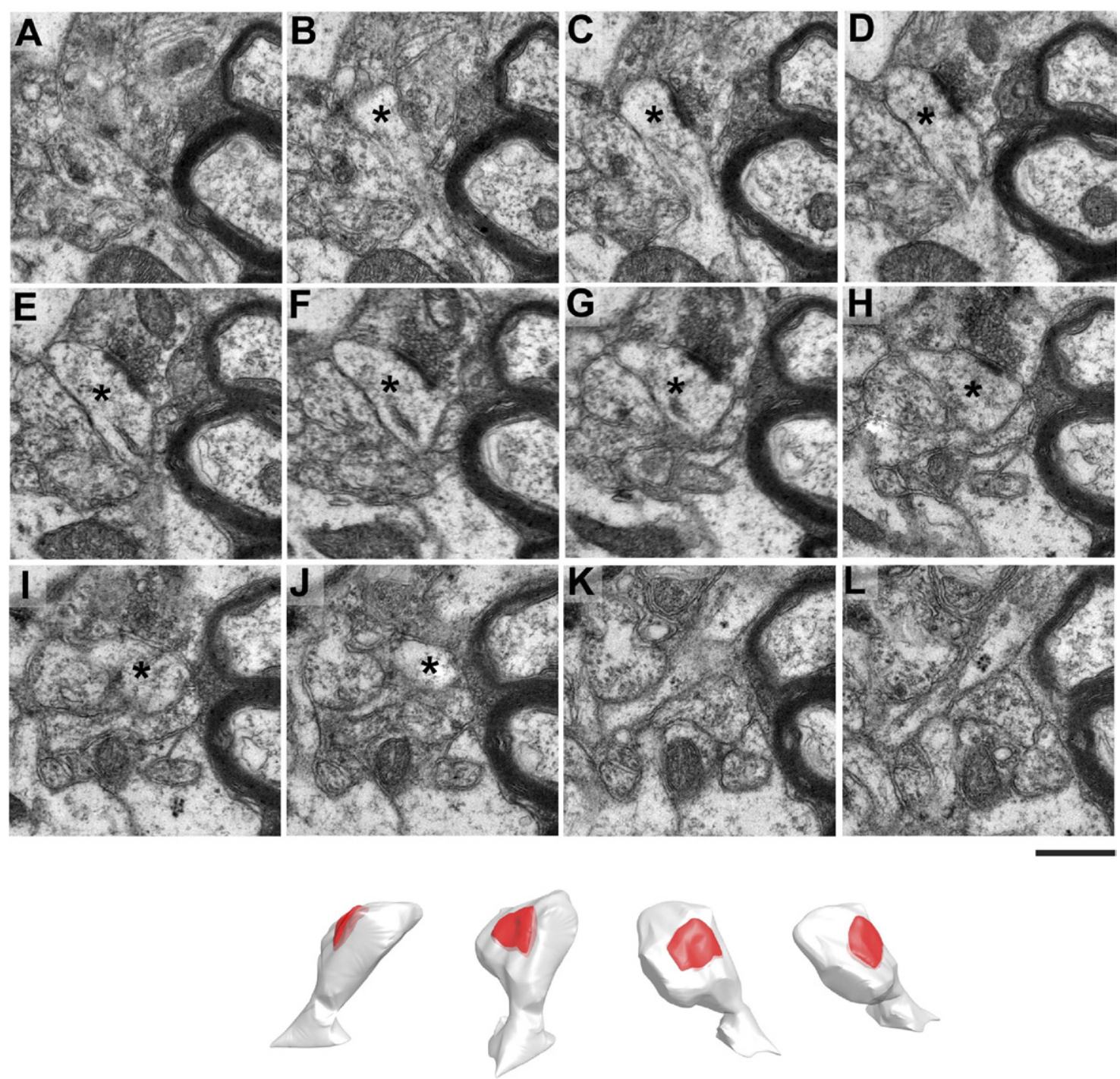

Fig. 2. Serial reconstruction of a spine in CA3 SL-M. The series of 12 electron photomicrographs shown in (A-L) represent a portion of a typical serial series used to reconstruct the synaptic microcircuitry in SL-M. The asterisks in (B-J) indicate a spine that was reconstructed in this series; four different views of that reconstructed spine and its postsynaptic density (red) are shown at the bottom of the figure. Scale bar: $0.5 \mu \mathrm{m}$.

clm.utexas.edu/). For each serial section, an $8 \mu \mathrm{m} \times 8 \mu \mathrm{m}$ sampling frame was placed in corresponding locations on the aligned images. Within these defined frame areas, all synapses were identified in each section in the series. Using this method, the entirety of individual synapses could be visualized and were reconstructed across serial sections. Fig 2 illustrates an example of a macular synapse, visualized in serial sections and reconstructed along with the dendritic spine (asterisk) on which it is located. In this manner, all synapses contained within a volume of $150-200 \mu \mathrm{m}^{3}$ in SL-M were reconstructed and quantified. Reconstruction of the synapses and dendritic spines permitted synapse classification by morphology and target as well as determination of the postsynaptic density (PSD) area and spine surface area and volume. Synapses were classified as (1) either axo-spinous or axo-dendritic based on whether they terminated on a dendritic spine or dendritic shaft (Fig. 3), and (2) either macular or complex based on whether the reconstructed PSD demonstrated a simple, disk-shaped form or contained either partial or complete discontinuities (Fig. 4). Complex synapses included perforated, segmented, and partitioned PSDs (Donohue et al., 2006; Ganeshina et al., 2004a,b; Mezey et al., 2004; Stewart et al., 2005; Toni et al., 2001). Due to the very small numbers of these individual types of complex synapses, all three types were combined for the statistical analysis in order to increase the statistical power.

Quantification of all of the synapses in our 3-D reconstructed samples yielded the number of synapses for a known tissue volume. In order to control for the unlikely possibility of differential tissue shrinkage between groups, we normalized the number of synapses in each classification to the number of pyramidal cells. Pyramidal cell number was determined stereologically at the light microscopic level with Stereolnvestigator software (MicroBrightField, Inc., Colchester, VT, USA) from dissector pairs of toluidine blue stained $1 \mu \mathrm{m}$ sections cut from the same tissue block and distributed in a systematically random manner throughout SL-M as described previously (Newton et al., 2007; Shi et al., 2007).

\section{Statistical analysis}

Statistical analyses were performed with SPSS software (version 16.0 for Windows, SPSS Inc., Chicago, IL, USA). A one-way analysis of variance (ANOVA) with a Bonferroni post hoc test was used to assess the effect of group on the dependent variables among groups. Statistical significance was defined as $P<0.05$ and 
axo-spinous synapses
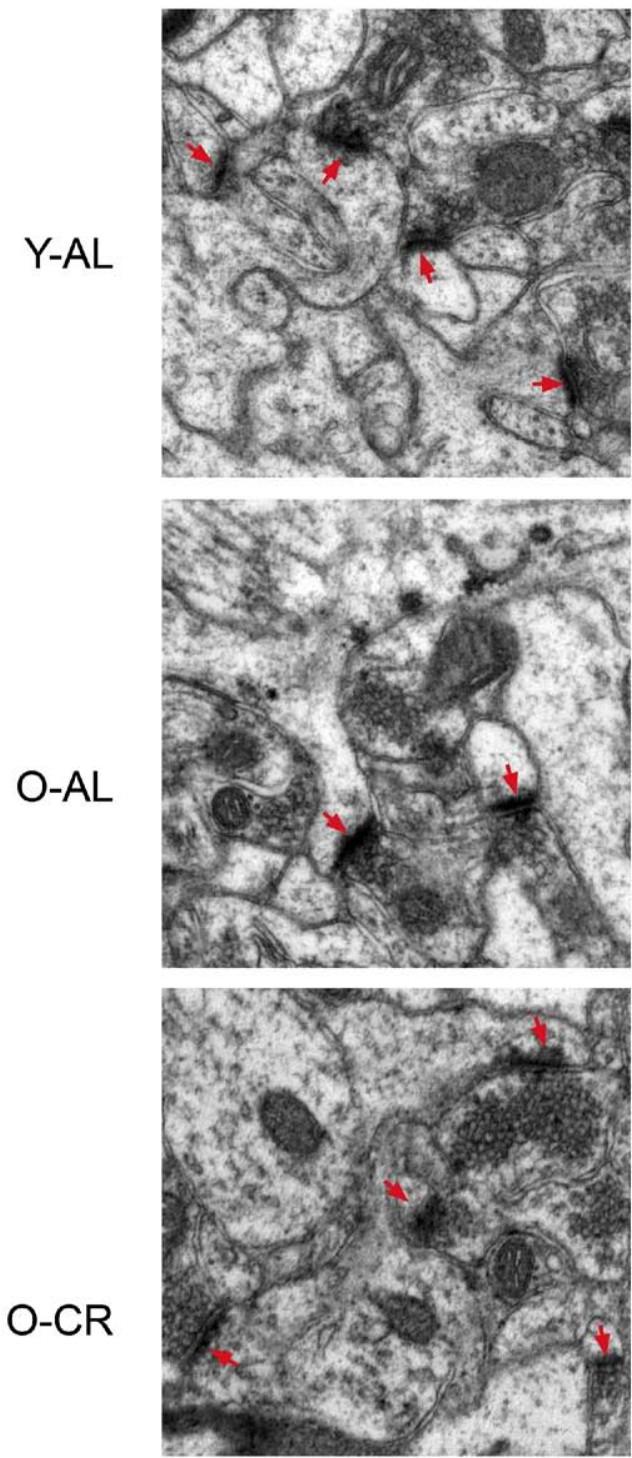

axo-dendritic synapses
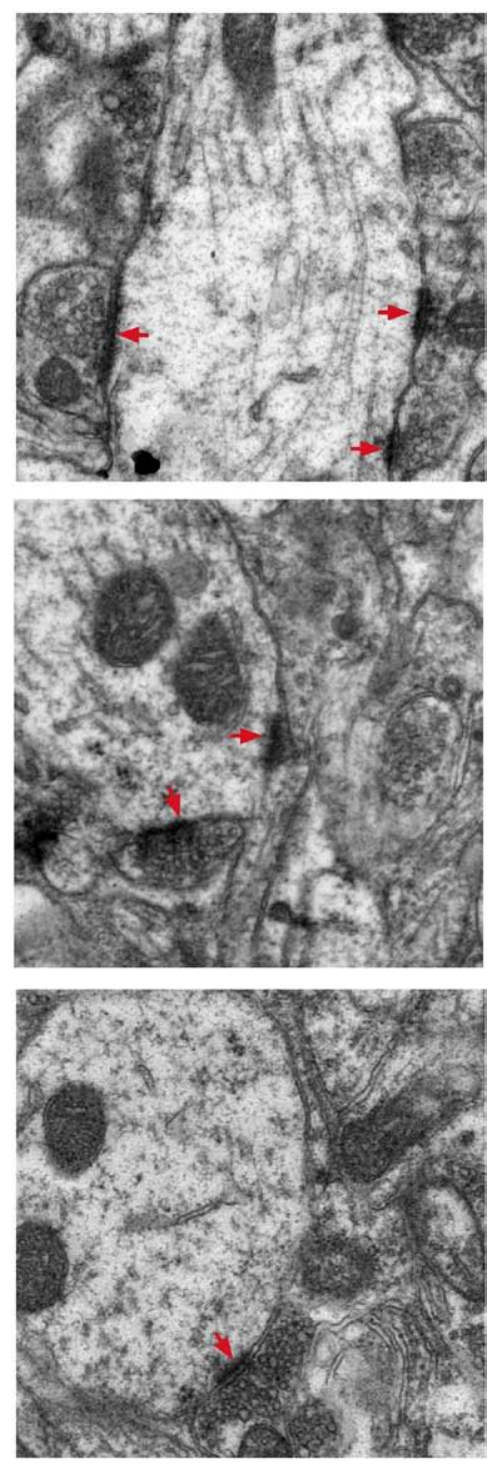

Fig. 3. Axo-spinous and axo-dendritic synapses in CA3 SL-M of young AL, old AL, and old CR rats. Electron micrographs illustrating tissue ultrastructure and representative examples of axo-spinous and axo-dendritic synapses in the SL-M of young AL, old AL and old CR rats. Both types of synapses were observed in all groups and no gross abnormalities were observed. Y-AL, young ad libitum fed; O-AL, old ad libitum fed; O-CR, old caloric restricted. Red arrows indicate synapses. Scale bar: $0.5 \mu \mathrm{m}$.

a Bonferroni adjustment was used for multiple comparisons to control for a type I error. Correlational analysis (Pearson's $r$ ) was performed to explore relationships between discrete dependent variables within different individual subjects.

\section{RESULTS}

\section{Body weight}

Food consumption for all animals was determined daily, and body weight was checked weekly to monitor health. Consistent with our previous reports (Adams et al., 2008; Newton et al., 2007; Shi et al., 2007), mean body weight varied significantly with both age and diet $\left(F_{(2,14)}=195.36\right.$, $P<0.0001)$. For $A L$ rats, the average weight at 29 months
(558 $\mathrm{g} \pm 20)$ was higher than that at 10 months ( $425 \mathrm{~g} \pm 26$; $P<0.0001)$. In addition, the average weights of both the young (425 $\mathrm{g} \pm 26)$ and old $A L(558 \mathrm{~g} \pm 20)$ groups were significantly higher than that of the old CR rats $(311 \mathrm{~g} \pm 8$; both $P$-values $<0.0001)$. Although $\mathrm{CR}$ rats were leaner than $\mathrm{AL}$ rats, they appeared healthy and had full coats of fur.

\section{Tissue ultrastructure in $A L$ and $C R$ rats}

Qualitative examination of the ultrastructure of tissue samples across groups revealed comparable quality in all groups with no evidence of gross abnormalities (Fig. 3). During all phases of the present study, the experimenter was blind to the age and dietary group of the animals from 

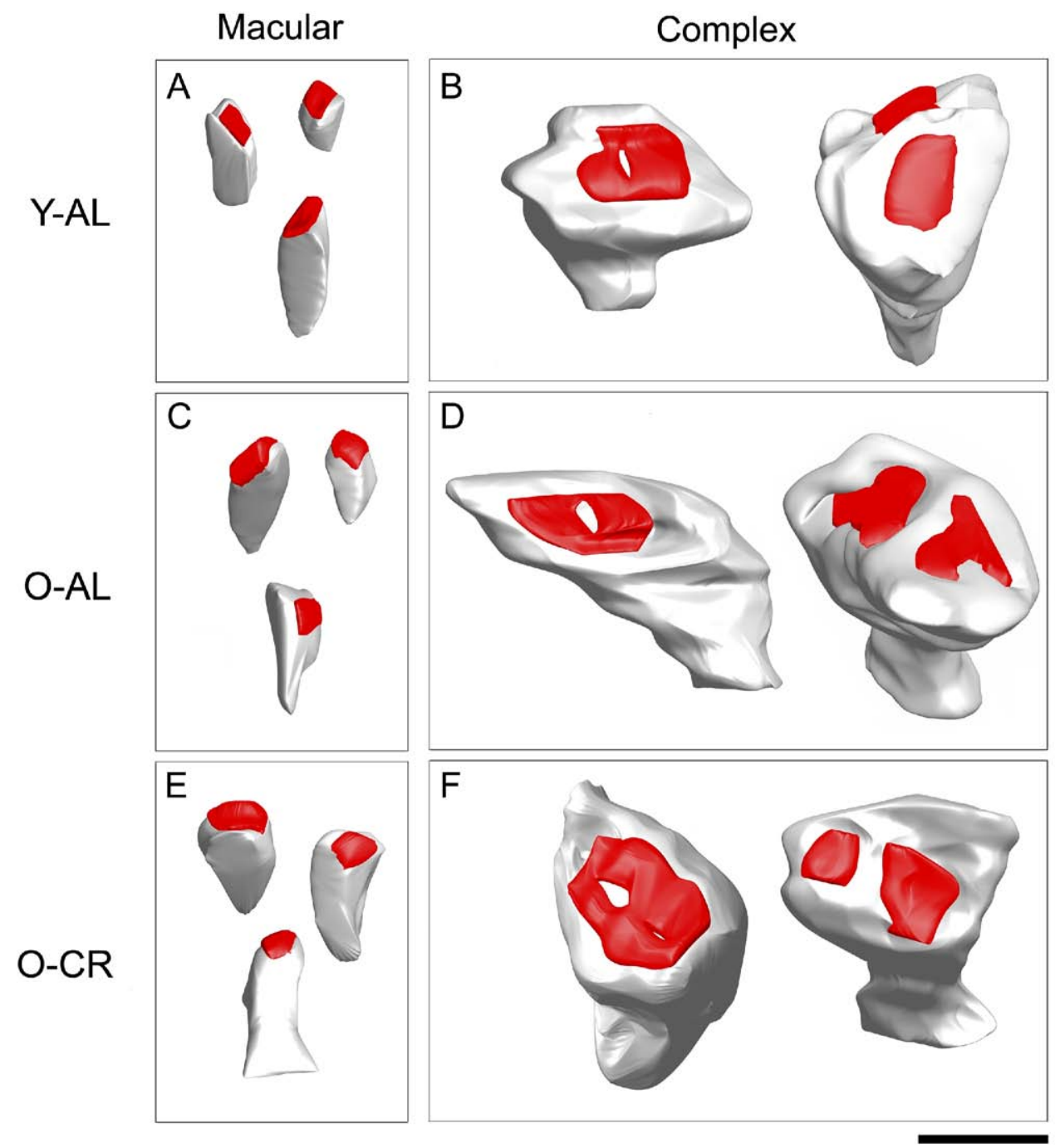

Fig. 4. Serial reconstructions of postsynaptic densities (PSD) and spines in CA3 SL-M of young AL, old AL, and old CR rats. Based on the PSD morphology, synapses were classified as macular or complex. Macular synapses demonstrated a simple, disk-shaped form; complex synapses demonstrated either partial or complete discontinuities (see Methods). Both types of synapses [macular (A, C, E) and complex (B, D, F)] and a similar range of spine morphologies were found in the all groups. Y-AL, young ad libitum fed; O-AL, old ad libitum fed; O-CR, old caloric restricted. Scale bar: $0.5 \mu \mathrm{m}$.

which tissue samples were taken and in no case were differences in the tissue quality among groups detectable.

All axo-spinous and axo-dendritic synapses (Fig. 3) were quantified within a defined volume of SL-M (approximately $200 \mu \mathrm{m}^{3}$ ). Synapses were identified by a darkly stained membrane corresponding to the PSD and the presence of at least two synaptic vesicles in the presynaptic bouton (Peters and Palay, 1991). Synapses were classified according to whether they were located on dendritic spines (axo-spinous; Fig. 3) or dendritic shafts (axodendritic; Fig. 3). Each axo-spinous and axo-dendritic synapse was reconstructed and the PSD area determined. Based on morphology, each synapse was further classified either as macular (Fig. 4A, C, E) or complex (including perforated, segmented, and all other non-macular contacts; Fig. 4B, D, F). In addition, the postsynaptic spine of each axo-spinous synapse was reconstructed and the spine surface area and volume determined. Qualitatively, we observed a similar range of synapse and spine morphologies in all animal groups (representative examples for each group are shown in Fig. 4).

\section{CA3 synapse numbers}

Only by using 3-D serial reconstruction is it possible to reliably distinguish macular from complex synapses that have been associated with age-related learning impairments (Nicholson et al., 2004) and functional plasticity such as LTP and long-term depression (LTD) (Geinisman et al., 1991, 1993, 1996; Mezey et al., 2004). Once the total number of synapses of each type in the reconstructed tissue sample was determined, synapse numbers were normalized to the stereologically determined number of neurons in that tissue sample as described in the Methods. 


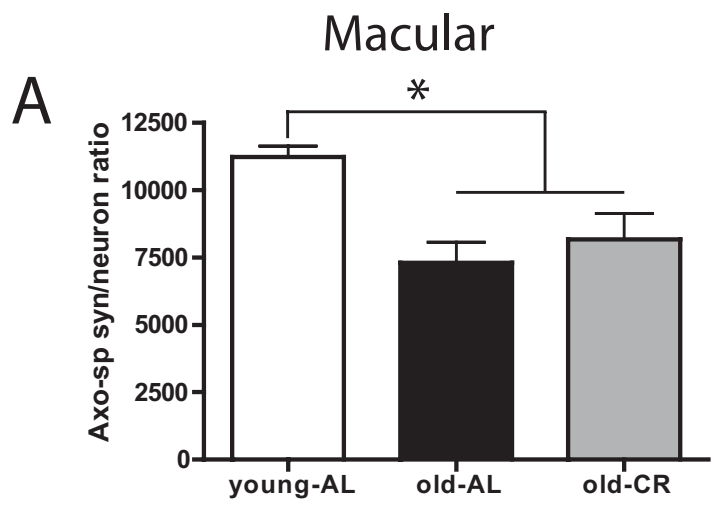

B
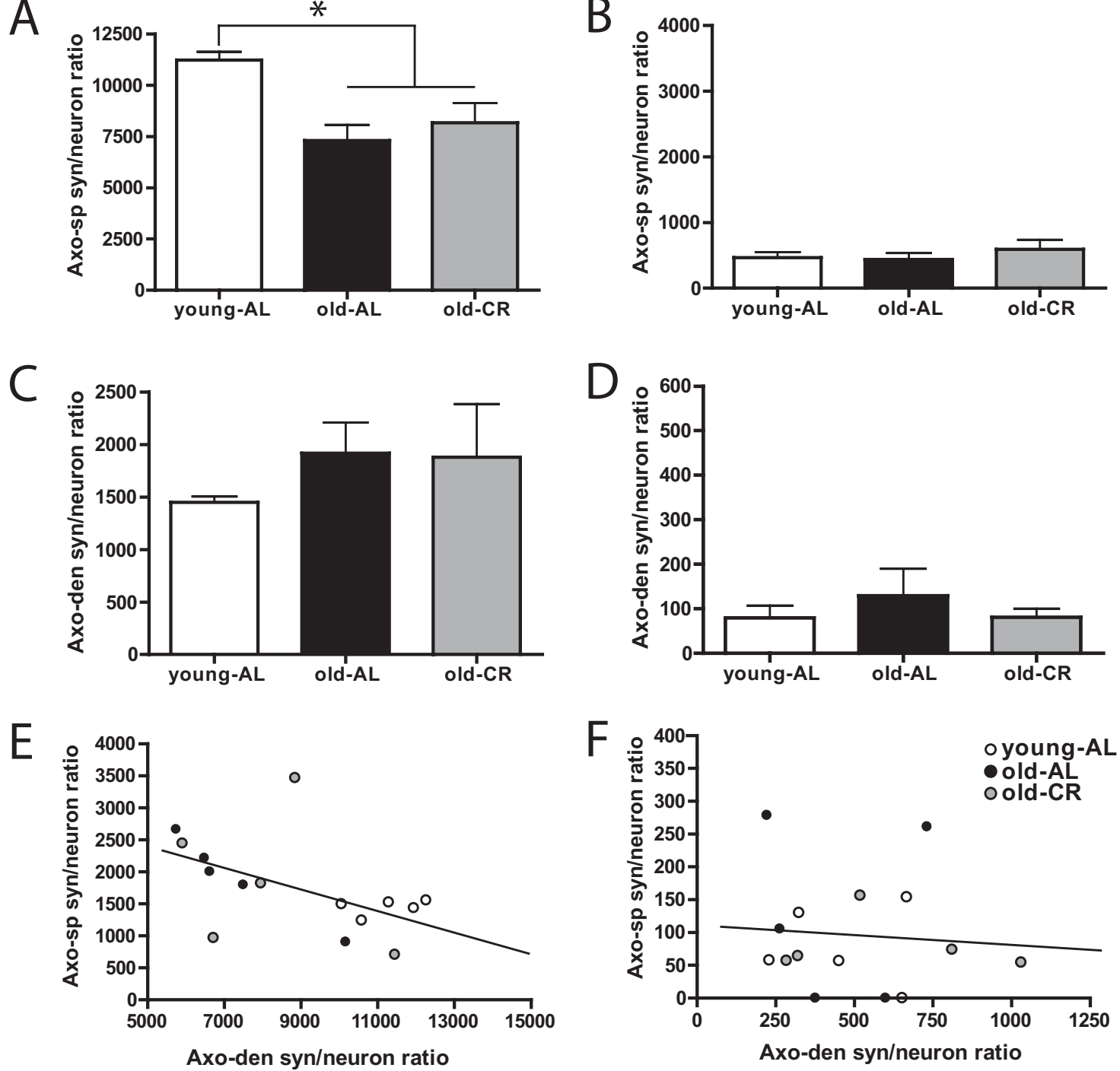

Fig. 5. Quantification of macular and complex synapses terminating on spines and dendrites in CA3 SL-M of young AL, old AL, and old CR rats. The total number synapses of each type in the reconstructed volume of S-LM was normalized to the stereologically determined number of neurons in that tissue block. An ANOVA revealed a main effect on macular axo-spinous synapses (A), but not complex axo-spinous synapses (B). Post hoc analysis indicated that the number of macular axo-spinous synapses decreased with age $(P<0.05$; * indicates significant decrease from young-AL group), but was not reversed by CR. No significant differences were observed for macular (C) or complex (D) axo-dendritic synapses. Data are presented as mean \pm standard error of the mean $(n=5)$. Correlational analysis revealed a significant negative correlation between macular axo-spinous and axo-dendritic synapses $(r=-0.51, P=0.051 ; \mathrm{E})$, indicating that axo-dendritic synapses increased as axo-spinous synapses decreased. No relationship was observed for the complex axo-spinous and axo-dendritic synapses (F). Young-AL, young ad libitum fed rats (open bars); Old-AL, old ad libitum fed rats (black bars); Old-CR, old caloric restricted rats (gray bars). Axo-sp, Axo-spinous; Axo-den, Axo-dendritic.

Fig 5 illustrates the resulting synapse per neuron ratio for macular and complex synapses terminating on spines and dendritic shafts for each of the three groups in our study.

Our data revealed a significant main effect of group for macular synapses terminating on spines $\left(F_{(2,14)}=7.584\right.$, $P<0.01$; Fig. 5A). Post hoc analysis indicated a significant effect of age such that both old $A L$ and $C R$ rats had significantly fewer macular axo-spinous synapses than young AL fed animals (both $P$-values $<0.05$; Fig. $5 \mathrm{~A}$ ). Moreover, there was no difference between old $A L$ and $C R$ fed animals $(P=1.00$; Fig. $5 \mathrm{~A})$. In contrast to the age- related decline in macular axo-spinous synapses, no difference among groups was detected for complex axospinous synapses $\left(F_{(2,14)}=0.544, P>0.5\right.$; Fig. $\left.5 \mathrm{~B}\right)$, suggesting that complex synapses contacting spines are more stable across lifespan than are macular synapses, and also that the decline in macular synapses is not accompanied by an increase in complex synapses.

Interestingly, the pattern of change in macular axodendritic synapses appeared to mirror that seen across lifespan for macular synapses contacting spines. Although no significant group effect was detected $\left(F_{(2,14)}=0.595\right.$, 
$P>0.5$; Fig. 5C), a trend for macular synapses on dendritic shafts to be more numerous than on spines was observed in both old $A L$ and $C R$ rats compared to the young group. No effect of age or diet was detected or trend observed for complex synapses contacting dendritic shafts $\left(F_{(2,14)}=\right.$ $0.493, P>0.6$; Fig. 5D). In order to assess whether a relationship existed between the significant age-related decrease in macular axo-spinous synapses and the apparent age-related increase in macular axo-dendritic synapses, we performed a correlational analysis within individual animals. Fig 5E illustrates the results of that analysis and demonstrates a significant inverse relationship between axo-spinous and axo-dendritic macular synapses $(r=-0.51 ; P=0.051)$ indicating that more macular synapses contact dendritic shafts as the prevalence of macular synapses contacting spines decreases with age. No such relationship exists for complex axo-spinous and axodendritic synapses $(r=-0.08 ; P=0.76$; Fig. $5 \mathrm{~F})$.

\section{CA3 synapse size}

As changes in synapse number could be accompanied by compensatory changes in PSD area, and changes in PSD area have been associated with altered excitatory transmission and plasticity (Desmond and Levy, 1986; Ganeshina et al., 2004a,b; Nicholson et al., 2006; Nicholson and Geinisman, 2009; Stewart et al., 2005; Takumi et al., 1999), we also measured the PSD surface area of all reconstructed synapses. The results demonstrated no effect of age or diet on PSD size (all $P$-values $>0.25$; Table 1). Thus, as synapses decrease in number, there is no concomitant change in the surface area of the PSD suggesting that synapse size is independent of age and dietary condition.

The majority of excitatory transmission in the hippocampus occurs at spinous synapses and previous reports have indicated that the morphology of hippocampal spines is plastic, fluctuating with changes in hormone levels, learning and memory, and environmental complexity (De et al., 2008; Jedlicka et al., 2008; Knott and Holtmaat,

Table 1. Synapse and spine areas and volumes in young AL, old AL, and old CR rats

\begin{tabular}{llll}
\hline & Young AL & Old AL & Old CR \\
\hline $\begin{array}{l}\text { Synapse size } \\
\text { Axo-spinous synapse surface } \\
\text { area macular }\left(\mu \mathrm{m}^{2}\right)\end{array}$ & 0.049 & 0.050 & 0.051 \\
$\begin{array}{c}\text { Axo-spinous synapse surface } \\
\quad \text { area complex }\left(\mu \mathrm{m}^{2}\right)\end{array}$ & 0.193 & 0.161 & 0.181 \\
$\begin{array}{c}\text { Axo-dendritic synapse surface } \\
\quad \text { area macular }\left(\mu \mathrm{m}^{2}\right)\end{array}$ & 0.091 & 0.092 & 0.091 \\
$\begin{array}{c}\text { Axo-dendritic synapse surface } \\
\text { area complex }\left(\mu \mathrm{m}^{2}\right)\end{array}$ & 0.108 & 0.148 & 0.171 \\
$\begin{array}{c}\text { Spine size } \\
\text { Spine surface area }\left(\mu \mathrm{m}^{2}\right)\end{array}$ & 0.598 & 0.568 & 0.580 \\
$\quad$ Spine volume $\left(\mu \mathrm{m}^{3}\right)$ & 0.050 & 0.049 & 0.051 \\
\hline
\end{tabular}

No significant group differences were observed in any measure of the synapse or spine size. Data are reported as the group mean.
2008; Leuner and Shors, 2004; Sala et al., 2008). Therefore, we determined surface area and volume of the each postsynaptic spine in our 3-D serial reconstruction of SL-M. The results revealed no significant differences between groups in either measure (all $P$-values $>0.85$; Table $1)$, suggesting that spine morphometry, like PSD size, does not demonstrate a compensatory change in response to the age-related loss of macular axo-spinous synapses.

\section{DISCUSSION}

The present study investigated whether age and/or CR alter the functional microcircuitry of the SL-M in CA3 of the hippocampus. Using 3-D serial reconstruction, we quantified macular and complex synapses that terminated on dendritic spines and shafts as well as determined the size of the PSDs of those synapses and their postsynaptic spines. Our results demonstrated a significant age-related decline in macular axo-spinous synapses in SL-M that was correlated with an increase in macular axo-dendritic synapses. Complex synapses did not decline across lifespan, and no effect of CR was detected for any of the synapse classes in the present study. Finally, neither age nor CR affected the size of PSDs or postsynaptic spines.

Although quantitative electron microscopy has been used to evaluate age-related changes in the hippocampus, this is the first study to specifically evaluate the SL-M of CA3 using this technique. A previous stereological study reported a $24 \%$ overall decrease in CA3 synapses early in life, between 3 and 12 months (De Groot and Bierman, 1987). In the middle and inner molecular layers of the dentate gyrus, axo-spinous synapses have been reported to decrease between 5 and 28 months of age (Geinisman et al., 1992). However, stereological quantification of synapses in the middle molecular layer indicated no synapse decline from 10 through 29 months of age (Newton et al., 2007) suggesting a developmental reduction in the number of synapses in the dentate gyrus followed by a synaptic stability from adulthood through old age. In CA1, no quantitative change in synapses was detected in stratum radiatum either between 6 and 29 months (Geinisman et al., 2004) or from 10 through 29 months (Shi et al., 2007). Similarly, stereological quantification of synapses at the electron microscopic level in stratum lucidum of CA3 revealed no change across lifespan (Poe et al., 2001). In contrast, the present observation of an age-related synapse loss in SL-M of CA3 suggests that this layer may be uniquely sensitive to aging. This observation corroborates the results of a light microscopic study suggesting circuitspecific synaptic changes in the hippocampus across the life span (Adams et al., 2008; Smith et al., 2000). In the latter study, using immunodetection of synaptophysin within the layers of each hippocampal regions as a synaptic marker, SL-M was the only layer in hippocampus that demonstrated significantly lower levels of synaptophysin in old, learning impaired rats compared either to young or old, unimpaired rats.

The age-related decline in SL-M synapses parallels the well-documented cognitive decline that occurs across the 
life span. It has been reported that progressive cognitive impairment was attenuated by caloric restriction as old CR rats performed significantly better on the MWM test of spatial learning and memory than age-matched $A L$ rats (Adams et al., 2008; Markowska and Savonenko, 2002). The present results, however, indicated that both old CR and $A L$ rats had fewer synapses than the young group. These findings suggest that cellular mechanisms, rather than alterations in synapse number, may underlie the higher cognitive functioning found in old CR rats. Consistent with this notion, we have previously reported an agerelated decline in glutamate receptor subunit levels in hippocampus that is prevented by CR (Adams et al., 2008; Newton et al., 2007; Shi et al., 2007). Moreover, both NMDA and AMPA subunits in CA3 are significantly more abundant in old CR than old AL rats (Adams et al., 2008), and future immunogold studies will assess whether these changes are found at the synapse. Interestingly, CR has been reported to prevent the age-related decline in LTP as well as in the hippocampal expression of the NR1 subunit of NMDA receptors (Eckles-Smith et al., 2000). Thus, CR may enhance synaptic plasticity by altering synaptic protein levels in the hippocampus to compensate for a synaptic loss.

The size of hippocampal synapses has been repeatedly associated with measures of hippocampal function. For example, aged animals with impaired cognition have been reported to demonstrate reductions in the surface area of synapses (Nicholson et al., 2004), and the PSD area of specific types of synapses in young rats increased both as a function of learning (Geinisman et al., 2004) and with LTP induction in the hippocampus (Geinisman et al., 1991, 1993, 1996; Weeks et al., 1999, 2001). Previous reports also have indicated that the abundance of AMPA-type glutamate receptors is related to the size and complexity of the PSD (Ganeshina et al., 2004a,b; Nicholson et al., 2006; Nicholson and Geinisman, 2009). As old CR rats have both higher levels of AMPA receptor subunits in CA3 (Adams et al., 2008) and better cognitive performance than old $A L$ rats (Adams et al., 2008; Markowska and Savonenko, 2002), we hypothesized that PSDs might be larger size in old $C R$ than old $A L$ rats in the present study. Nevertheless, our results demonstrated no greater PSD size or number of complex synapses in old CR rats.

Spine surface area and volume also did not differ between groups and thus provided no morphological evidence of spine plasticity in response to age or diet. Although no compensatory change in dendritic spine morphology was detected in SL-M, age-related or a CR-induced changes impacting cognitive function could occur in a different layer or region of the hippocampus. Such region-specific dendritic changes in the hippocampus have been shown in response to manipulations such as ovarian steroids and stress induction. For example, estrogen increased spine number in the CA1 region of the hippocampus, but had no effect on the dentate gyrus or CA3 region (Woolley et al., 1990a). Moreover, exposure to excessive glucocorticoids altered dendritic morphology only in CA3 causing atrophy of the apical, but not basal, dendrites in the stratum oriens (Woolley et al., 1990b). These data support the idea that even in a single hippocampal region, manipulations of the cellular microenvironment can produce differential dendritic responses across layers.

Our data suggest an age-related shift in the relative abundance of axo-spinous and axo-dendritic synapses. In a previous study examining the effects of LTP and LTD on the functional microcircuitry of the dentate gyrus, it was observed that LTP of the medial perforant path led to an increase in axo-spinous synapses, and that LTD was associated with an increase in axo-dendritic synapses (Mezey et al., 2004). That report supports the idea that the inverse correlation in macular axo-spinous and axo-dendritic synapse numbers observed here may be associated with functional alterations within the hippocampus. Consistent with this possibility are the observed age-related decreases in hippocampal LTP (Eckles-Smith et al., 2000; Molina et al., unpublished observations) and the propensity of aged animals for increased LTD (Foster and Kumar, 2007; Kumar and Foster, 2005; Norris et al., 1996). An increase in the amount of LTD would likely keep the synapses from being able to be strengthened and alter the excitatory/inhibitory balance, and thus, could contribute to some of the memory losses observed with aging.

The results of this study of the microcircuitry of S-LM of CA3 provide the first ultrastructural evidence that macular synapses in this layer demonstrate a unique vulnerability to aging. Nevertheless, PSD size and spine surface area and volume are stable between young and old age. Moreover, despite the age-related loss of macular axo-spinous synapses and the previously reported CR-induced benefits for behavior and glutamate receptors in old animals, no effect of CR on the measures of S-LM microcircuitry evaluated in the present study were detected. Accordingly, the behavioral benefits of CR may be mediated by the effects of CR on synaptic protein levels in CA3 in conjunction with cellular and functional alterations elsewhere in the hippocampus.

Acknowledgments-This work was supported by NIH grants: NIA PO1 AG11370, RO1 AG019886, and KO1 AG027828.

\section{REFERENCES}

Adams MM, Shi L, Linville MC, Forbes ME, Long $A B$, Bennett $C$, Newton IG, Carter CS, Sonntag WE, Riddle DR, Brunso-Bechtold JK (2008) Caloric restriction and age affect synaptic proteins in hippocampal CA3 and spatial learning ability. Exp Neurol 211: 141-149.

Cabalka LM, Hyman BT, Goodlett CR, Ritchie TC, Van Hoesen GW (1992) Alteration in the pattern of nerve terminal protein immunoreactivity in the perforant pathway in Alzheimer's disease and in rats after entorhinal lesions. Neurobiol Aging 13:283-291.

De Groot DMG, Bierman EPB (1987) Numerical changes in rat hippocampal synapses. An effect of "aging"? Acta Stereol 6:53-58.

De RM, Klauser P, Garcia PM, Poglia L, Muller D (2008) Spine dynamics and synapse remodeling during LTP and memory processes. Prog Brain Res 169:199-207.

Desmond NL, Levy WB (1986) Changes in the postsynaptic density with long-term potentiation in the dentate gyrus. J Comp Neurol 253:476-482.

Donohue HS, Gabbott PL, Davies HA, Rodriguez JJ, Cordero MI, Sandi C, Medvedev NI, Popov VI, Colyer FM, Peddie CJ, Stewart MG (2006) Chronic restraint stress induces changes in synapse 
morphology in stratum lacunosum-moleculare CA1 rat hippocampus: a stereological and three-dimensional ultrastructural study. Neuroscience 140:597-606.

Eckles-Smith K, Clayton D, Bickford P, Browning MD (2000) Caloric restriction prevents age-related deficits in LTP and in NMDA receptor expression. Brain Res Mol Brain Res 78:154-162.

Foster TC, Kumar A (2007) Susceptibility to induction of long-term depression is associated with impaired memory in aged Fischer 344 rats. Neurobiol Learn Mem 87:522-535.

Ganeshina O, Berry RW, Petralia RS, Nicholson DA, Geinisman Y (2004a) Differences in the expression of AMPA and NMDA receptors between axospinous perforated and nonperforated synapses are related to the configuration and size of postsynaptic densities. J Comp Neurol 468:86-95.

Ganeshina O, Berry RW, Petralia RS, Nicholson DA, Geinisman Y (2004b) Synapses with a segmented, completely partitioned postsynaptic density express more AMPA receptors than other axospinous synaptic junctions. Neuroscience 125:615-623.

Geinisman Y, Detoledo-Morrell L, Morrell F (1991) Induction of longterm potentiation is associated with an increase in the number of axospinous synapses with segmented postsynaptic densities. Brain Res 566:77-88.

Geinisman Y, Detoledo-Morrell L, Morrell F, Persina IS, Beatty MA (1996) Synapse restructuring associated with the maintenance phase of hippocampal long-term potentiation. J Comp Neurol 368:413-423.

Geinisman Y, Ganeshina O, Yoshida R, Berry RW, Disterhoft JF, Gallagher M (2004) Aging, spatial learning, and total synapse number in the rat CA1 stratum radiatum. Neurobiol Aging 25: 407-416.

Geinisman Y, Toledo-Morrell L, Morrell F, Heller RE, Rossi M, Parshall RF (1993) Structural synaptic correlate of long-term potentiation: formation of axospinous synapses with multiple, completely partitioned transmission zones. Hippocampus 3:435-445.

Geinisman Y, Toledo-Morrell L, Morrell F, Persina IS, Rossi M (1992) Age-related loss of axospinous synapses formed by two afferent systems in the rat dentate gyrus as revealed by the unbiased stereological dissector technique. Hippocampus 2:437-444.

Goto S, Hirano A (1990) Synaptophysin expression in the striatum in Huntington's disease. Acta Neuropathol 80:88-91.

Heinonen O, Soininen H, Sorvari H, Kosunen O, Paljarvi L, Koivisto E, Riekkinen PJ Sr (1995) Loss of synaptophysin-like immunoreactivity in the hippocampal formation is an early phenomenon in Alzheimer's disease. Neuroscience 64:375-384.

Jedlicka P, Vlachos A, Schwarzacher SW, Deller T (2008) A role for the spine apparatus in LTP and spatial learning. Behav Brain Res 192:12-19.

Knott G, Holtmaat A (2008) Dendritic spine plasticity—current understanding from in vivo] studies. Brain Res Rev 58:282-289.

Kumar A, Foster TC (2005) Intracellular calcium stores contribute to increased susceptibility to LTD induction during aging. Brain Res 1031:125-128.

Leuner B, Shors TJ (2004) New spines, new memories. Mol Neurobiol 29:117-130.

Markowska AL, Savonenko A (2002) Retardation of cognitive aging by life-long diet restriction: implications for genetic variance. Neurobiol Aging 23:75-86.

Martin B, Pearson M, Brenneman R, Golden E, Keselman A, Iyun T, Carlson OD, Egan JM, Becker KG, Wood W III, Prabhu V, de Cabo R, Maudsley S, Mattson MP (2008) Conserved and differential effects of dietary energy intake on the hippocampal transcriptomes of females and males. PLoS One 3:e2398.

Martin B, Pearson M, Kebejian L, Golden E, Keselman A, Bender M, Carlson O, Egan J, Ladenheim B, Cadet JL, Becker KG, Wood W, Duffy K, Vinayakumar P, Maudsley S, Mattson MP (2007) Sexdependent metabolic, neuroendocrine, and cognitive responses to dietary energy restriction and excess. Endocrinology 148:43184333.
Masliah E, Mallory M, Ge N, Alford M, Veinbergs I, Roses AD (1995) Neurodegeneration in the central nervous system of apoEdeficient mice. Exp Neurol 136:107-122.

Masliah E, Mallory M, Hansen L, DeTeresa R, Alford M, Terry R (1994) Synaptic and neuritic alterations during the progression of Alzheimer's disease. Neurosci Lett 174:67-72.

Masliah E, Mallory M, Hansen L, DeTeresa R, Terry RD (1993) Quantitative synaptic alterations in the human neocortex during normal aging. Neurology 43:192-197.

Mayhew M, Renganathan M, Delbono O (1998) Effectiveness of caloric restriction in preventing age-related changes in rat skeletal muscle. Biochem Biophys Res Commun 251:95-99.

Mezey S, Doyere V, De Souza I, Harrison E, Cambon K, Kendal CE, Davies H, Laroche S, Stewart MG (2004) Long-term synaptic morphometry changes after induction of long-term potentiation and long-term depression in the dentate gyrus of awake rats are not simply mirror phenomena. Eur J Neurosci 19:2310-2318.

Newton IG, Forbes ME, Legault C, Johnson JE, Brunso-Bechtold JK, Riddle DR (2005) Caloric restriction does not reverse aging-related changes in hippocampal BDNF. Neurobiol Aging 26:683-688.

Newton IG, Forbes ME, Linville MC, Pang H, Tucker EW, Riddle DR, Brunso-Bechtold JK (2007) Effects of aging and caloric restriction on dentate gyrus synapses and glutamate receptor subunits. Neurobiol Aging 29:1308-1318.

Nicholson DA, Geinisman Y (2009) Axospinous synaptic subtypespecific differences in structure, size, ionotropic receptor expression, and connectivity in apical dendritic regions of rat hippocampal CA1 pyramidal neurons. J Comp Neurol 512:399-418.

Nicholson DA, Trana R, Katz Y, Kath WL, Spruston N, Geinisman Y (2006) Distance-dependent differences in synapse number and AMPA receptor expression in hippocampal CA1 pyramidal neurons. Neuron 50:431-442.

Nicholson DA, Yoshida R, Berry RW, Gallagher M, Geinisman Y (2004) Reduction in size of perforated postsynaptic densities in hippocampal axospinous synapses and age-related spatial learning impairments. J Neurosci 24:7648-7653.

Norris CM, Korol DL, Foster TC (1996) Increased susceptibility to induction of long-term depression and long-term potentiation reversal during aging. J Neurosci 16:5382-5392.

Peters A, Palay SL (1991) The fine structure of the nervous system, neurons, and their supporting cells. Oxford, England: Oxford University Press.

Poe BH, Linville C, Riddle DR, Sonntag WE, Brunso-Bechtold JK (2001) Effects of age and insulin-like growth factor-1 on neuron and synapse numbers in area CA3 of hippocampus. Neuroscience 107:231-238.

Ramsey MM, Weiner JL, Moore TP, Carter CS, Sonntag WE (2004) Growth hormone treatment attenuates age-related changes in hippocampal short-term plasticity and spatial learning. Neuroscience 129:119-127.

Sala C, Cambianica I, Rossi F (2008) Molecular mechanisms of dendritic spine development and maintenance. Acta Neurobiol Exp Wars 68:289-304.

Shi L, Adams MM, Linville MC, Newton IG, Forbes ME, Long AB, Riddle DR, Brunso-Bechtold JK (2007) Caloric restriction eliminates the aging-related decline in NMDA and AMPA receptor subunits in the rat hippocampus and induces homeostasis. Exp Neurol 206:70-79.

Shi L, Poe BH, Constance LM, Sonntag WE, Brunso-Bechtold JK (2002) Caloric restricted male rats demonstrate fewer synapses in layer 2 of sensorimotor cortex. Brain Res 931:32-40.

Smith TD, Adams MM, Gallagher M, Morrison JH, Rapp PR (2000) Circuit-specific alterations in hippocampal synaptophysin immunoreactivity predict spatial learning impairment in aged rats. J Neurosci 20:6587-6593.

Stewart MG, Medvedev NI, Popov VI, Schoepfer R, Davies HA, Murphy K, Dallerac GM, Kraev IV, Rodriguez JJ (2005) Chemically induced long-term potentiation increases the number of perforated 
and complex postsynaptic densities but does not alter dendritic spine volume in CA1 of adult mouse hippocampal slices. Eur J Neurosci 21:3368-3378.

Takumi Y, Ramirez-Leon V, Laake P, Rinvik E, Ottersen OP (1999) Different modes of expression of AMPA and NMDA receptors in hippocampal synapses. Nat Neurosci 2:618-624.

Toni N, Buchs PA, Nikonenko I, Povilaitite P, Parisi L, Muller D (2001) Remodeling of synaptic membranes after induction of long-term potentiation. J Neurosci 21:6245-6251.

Weeks AC, Ivanco TL, Leboutillier JC, Racine RJ, Petit TL (1999) Sequential changes in the synaptic structural profile following longterm potentiation in the rat dentate gyrus. I. The intermediate maintenance phase. Synapse 31:97-107.
Weeks AC, Ivanco TL, Leboutillier JC, Racine RJ, Petit TL (2001) Sequential changes in the synaptic structural profile following longterm potentiation in the rat dentate gyrus. III. Long-term maintenance phase. Synapse 40:74-84.

Wetter TJ, Gazdag AC, Dean DJ, Cartee GD (1999) Effect of calorie restriction on in vivo] glucose metabolism by individual tissues in rats. Am J Physiol 276:E728E738.

Woolley CS, Gould E, Frankfurt M, McEwen BS (1990a) Naturally occurring fluctuation in dendritic spine density on adult hippocampal pyramidal neurons. J Neurosci 10:4035-4039.

Woolley CS, Gould E, McEwen BS (1990b) Exposure to excess glucocorticoids alters dendritic morphology of adult hippocampal pyramidal neurons. Brain Res 531:225-231. 